\title{
Cannabitwinol, a Dimeric Phytocannabinoid from Hemp, Cannabis sativa $L$., is a selective thermo-TRPs modulator
}

Giuseppina Chianese ${ }^{\dagger}$, Annalisa Lopatriello ${ }^{\dagger}$, Aniello Schiano Moriello ${ }^{\ddagger}$, Diego Caprioglio $^{\S}$, Daiana Mattoteia ${ }^{\S}$, Emanuele Benetti ${ }^{\wedge}$, Daniele Ciceri ${ }^{\wedge}$, Lolita Arnoldi ${ }^{\wedge}$, Eric De Combarieu^, Rosa Maria Vitale"l, Pietro Amodeo", Giovanni Appendino ${ }^{\S}$, Luciano De Petrocellis ${ }^{\ddagger}$ \& Orazio Taglialatela-Scafati ${ }^{\dagger, *}$

${ }^{\dagger}$ Department of Pharmacy, School of Medicine and Surgery, University of Naples Federico II, Via D. Montesano 49, 80131 Napoli, Italy

${ }^{\ddagger}$ Endocannabinoid Research Group (ERG) - Institute of Biomolecular Chemistry (ICB)-National Research Council (CNR), Via Campi Flegrei 34, 80078 Pozzuoli (NA), Italy

"Epitech Group SpA, Saccolongo, Padova, Italy

${ }^{\S}$ Dipartimento di Scienze del Farmaco, Università del Piemonte Orientale, Largo Donegani 2, 28100, Novara, Italy

^INDENA SpA, Via Don Minzoni 6, 20090 Settala, Milan, Italy

Institute of Biomolecular Chemistry (ICB)-National Research Council (CNR), Via Campi Flegrei 34, 80078 Pozzuoli (NA), Italy

\section{Table of Contents}

Figure S1. MS/MS spectra of cannabitwinol (3)

Figure S2. ${ }^{1} \mathrm{H}$ NMR spectrum of cannabitwinol $(3)(700 \mathrm{MHz})$ in $\mathrm{CD}_{3} \mathrm{OD}$ at $25^{\circ} \mathrm{C}$

Figure S3. ${ }^{1} \mathrm{H}$ NMR spectrum of cannabitwinol (3) $(700 \mathrm{MHz})$ in $\mathrm{CD}_{3} \mathrm{OD}$ at $-30{ }^{\circ} \mathrm{C}$

Figure S4. 2D NMR COSY spectrum of cannabitwinol (3) $(700 \mathrm{MHz})$ in $\mathrm{CD}_{3} \mathrm{OD}$ at $-30^{\circ} \mathrm{C}$ Figure S5. 2D NMR HSQC spectrum of cannabitwinol (3) $(700 \mathrm{MHz})$ in $\mathrm{CD}_{3} \mathrm{OD}$ at $-30{ }^{\circ} \mathrm{C}$ Figure S6. 2D NMR HMBC spectrum of cannabitwinol (3) $(700 \mathrm{MHz})$ in $\mathrm{CD}_{3} \mathrm{OD}$ at $-30^{\circ} \mathrm{C}$ Figure S7. 2D NMR ROESY spectrum of cannabitwinol (3) $(700 \mathrm{MHz})$ in $\mathrm{CD}_{3} \mathrm{OD}$ at $-30^{\circ} \mathrm{C}$ 


\section{SUPPORTING MATERIAL}

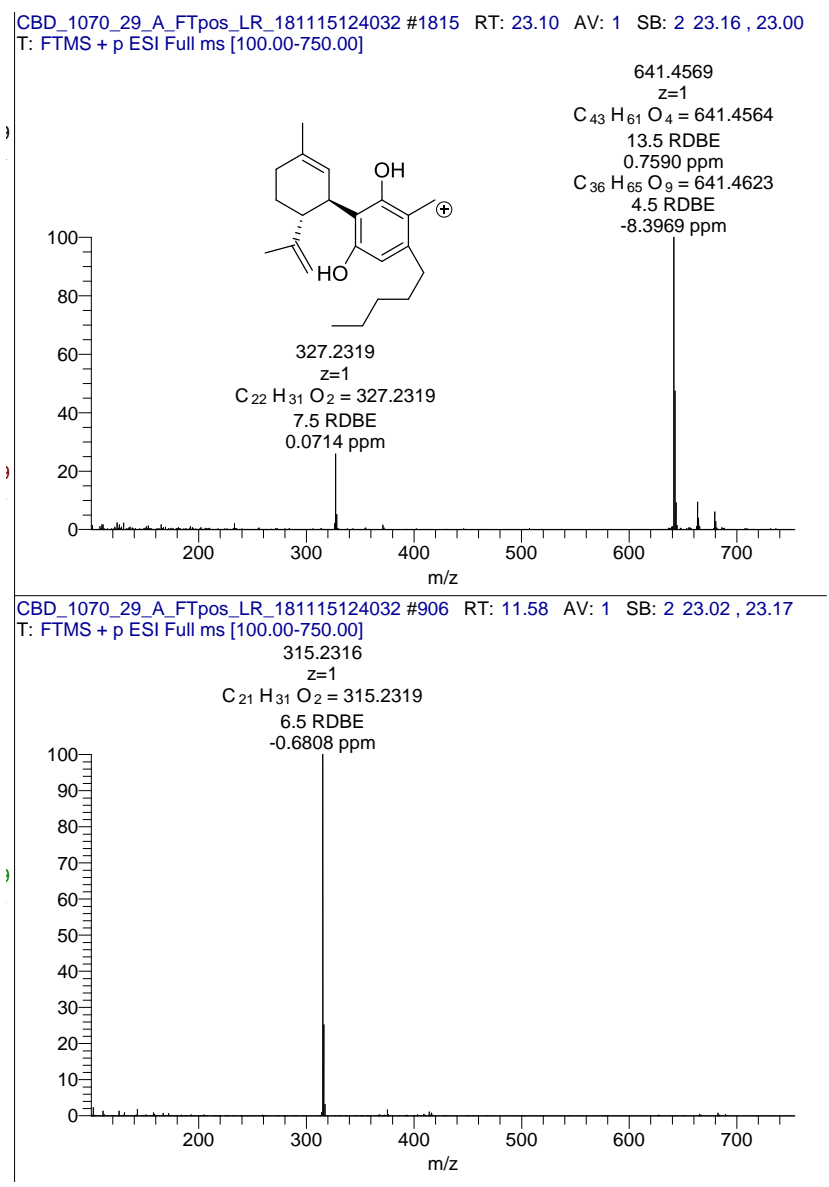

Figure S1. MS/MS spectra of cannabitwinol (3)

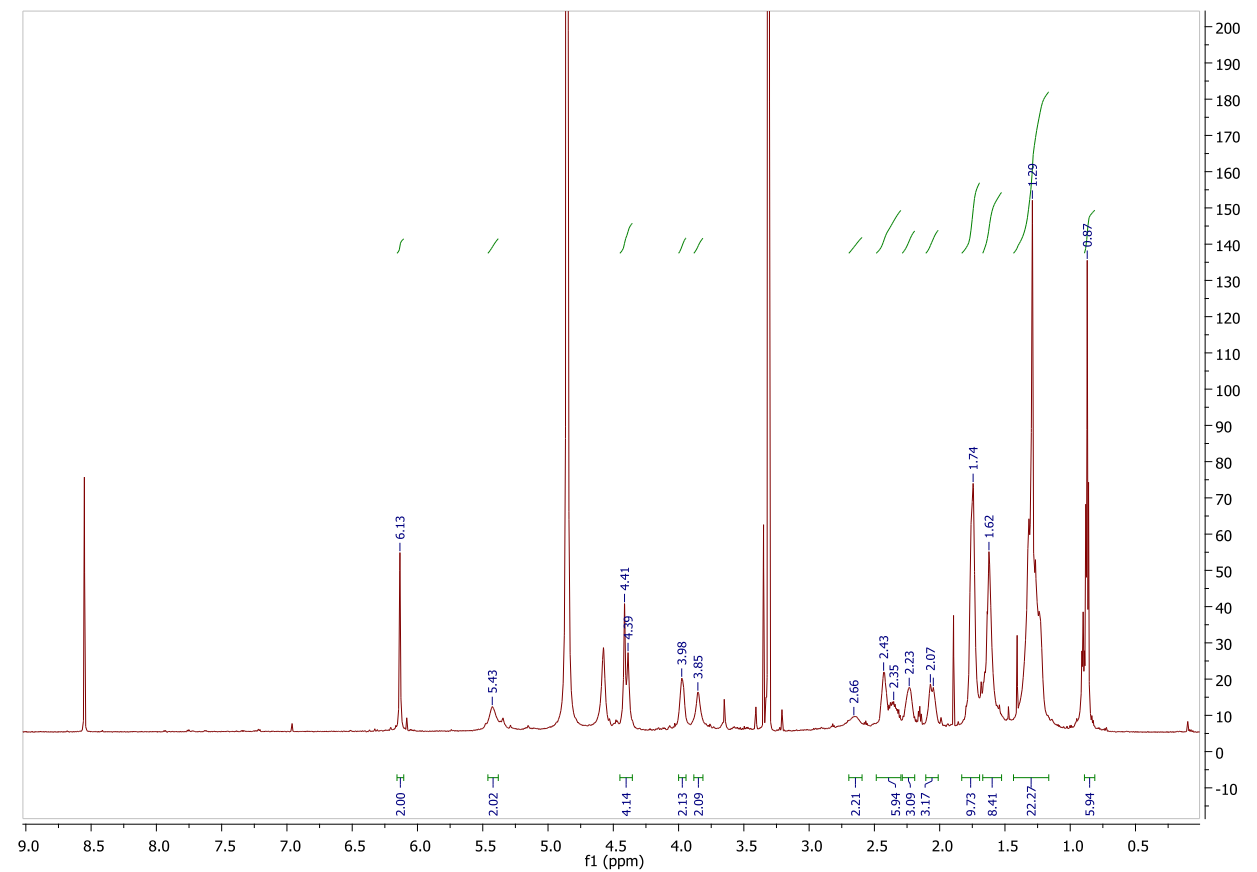

Figure S2. ${ }^{1} \mathrm{H}$ NMR spectrum of cannabitwinol $(3)(700 \mathrm{MHz})$ in $\mathrm{CD}_{3} \mathrm{OD}$ at $25^{\circ} \mathrm{C}$ 


\section{SUPPORTING MATERIAL}

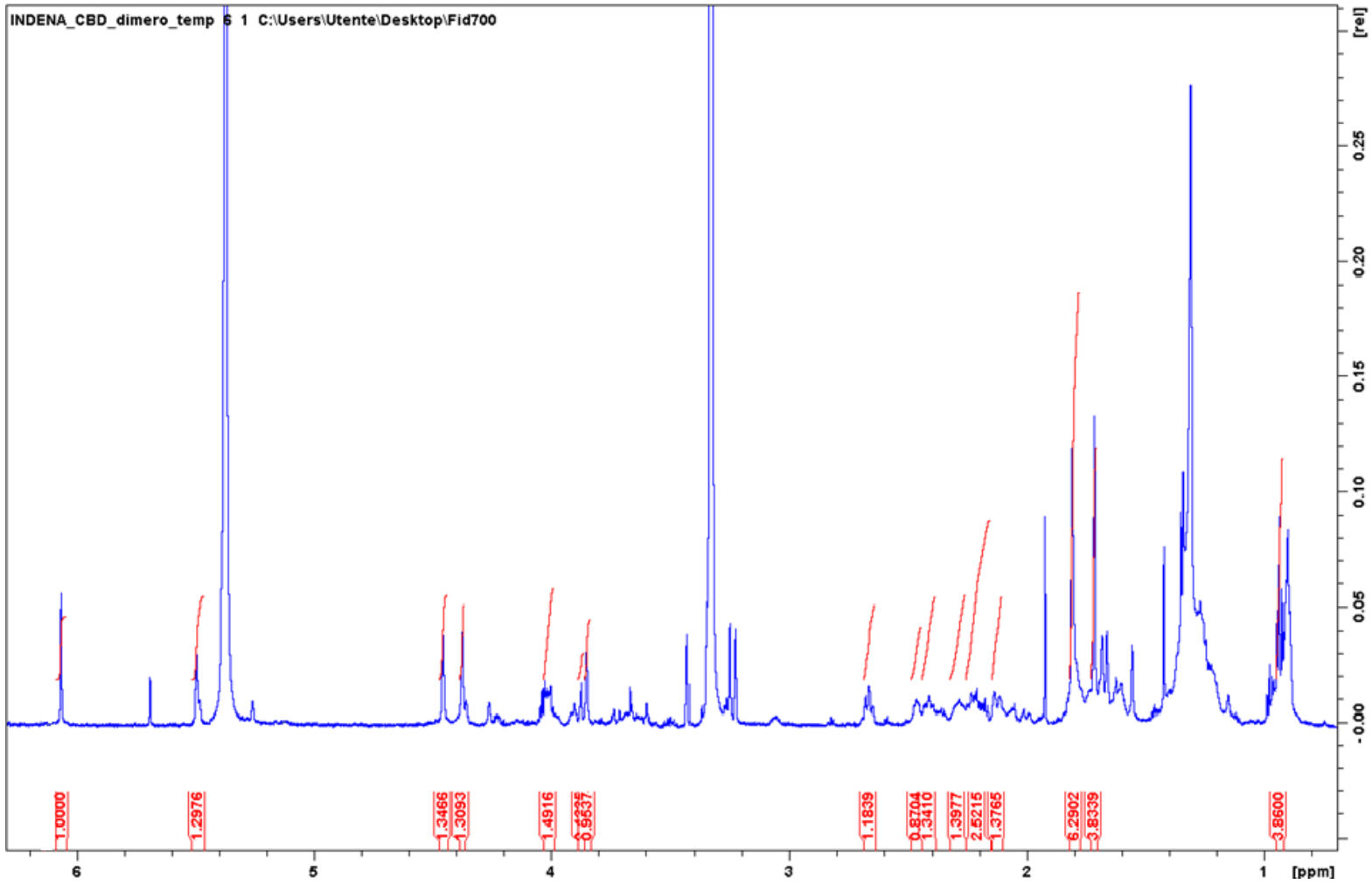

Figure S3. ${ }^{1} \mathrm{H}$ NMR spectrum of cannabitwinol (3) $(700 \mathrm{MHz})$ in $\mathrm{CD}_{3} \mathrm{OD}$ at $-30^{\circ} \mathrm{C}$

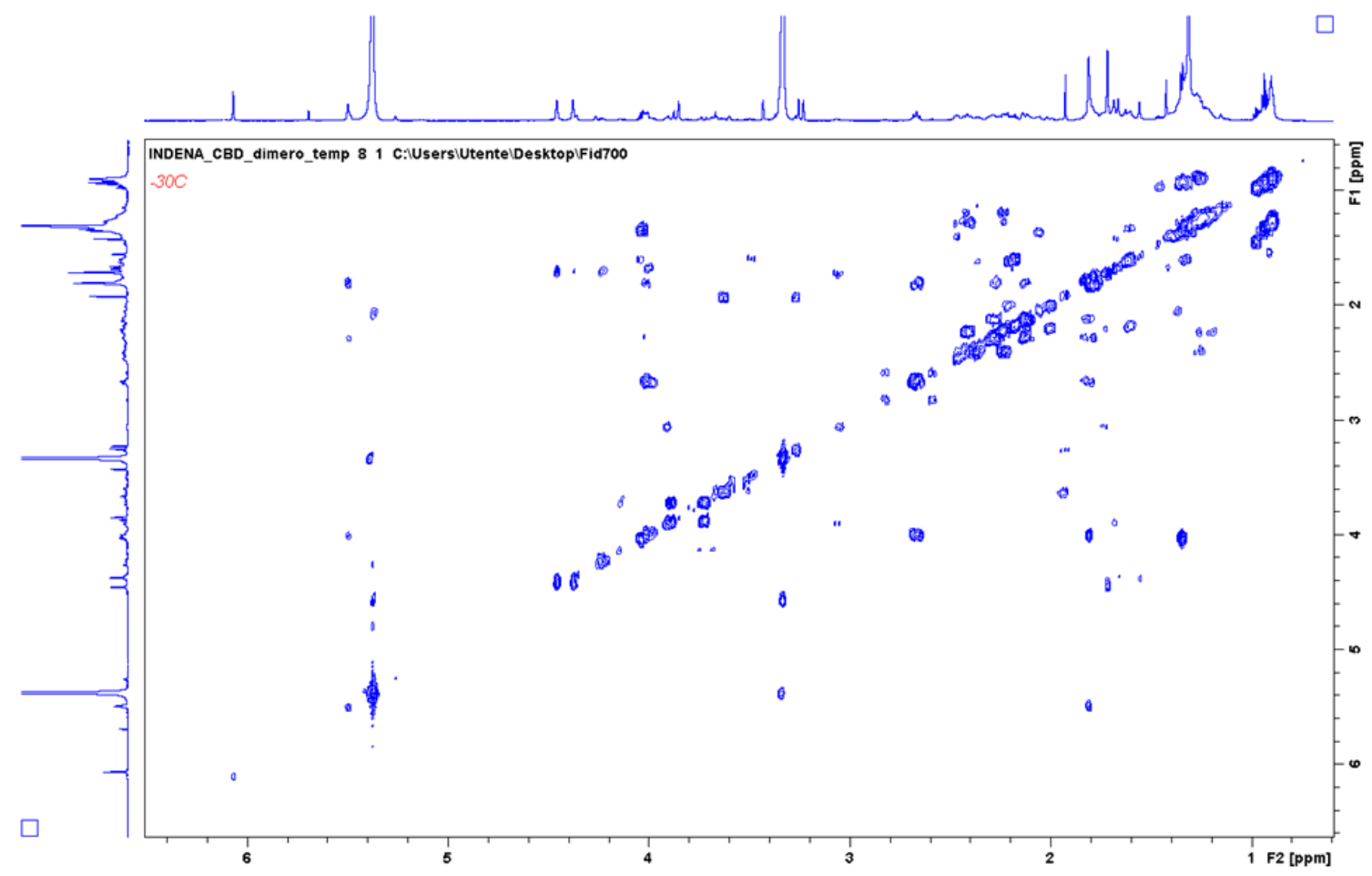




\section{SUPPORTING MATERIAL}

Figure S4. 2D NMR COSY spectrum of cannabitwinol (3) $(700 \mathrm{MHz})$ in $\mathrm{CD}_{3} \mathrm{OD}$ at $-30^{\circ} \mathrm{C}$

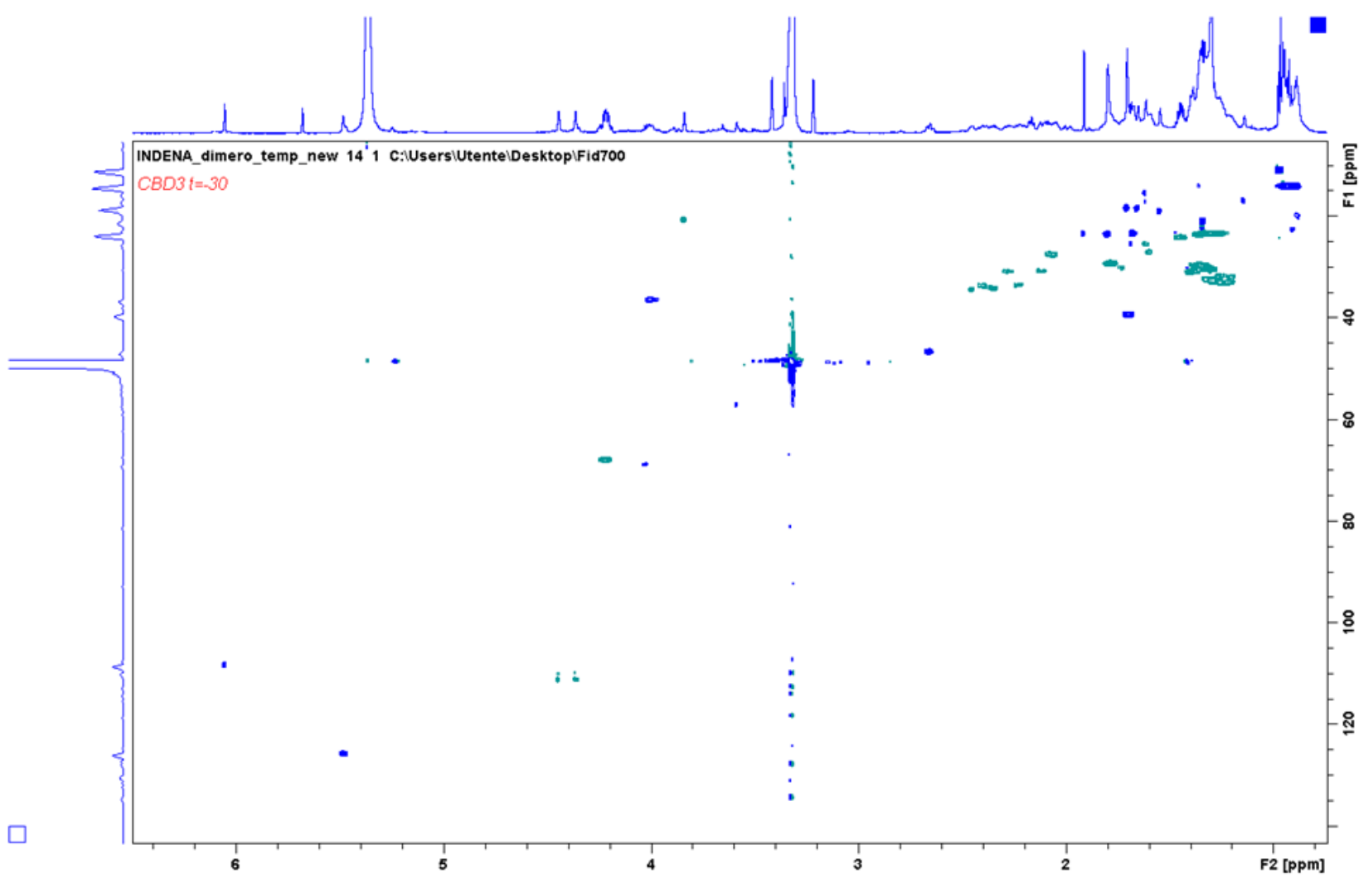

Figure S5. 2D NMR HSQC spectrum of cannabitwinol (3) $(700 \mathrm{MHz})$ in $\mathrm{CD}_{3} \mathrm{OD}$ at $-30^{\circ} \mathrm{C}$ 
SUPPORTING MATERIAL

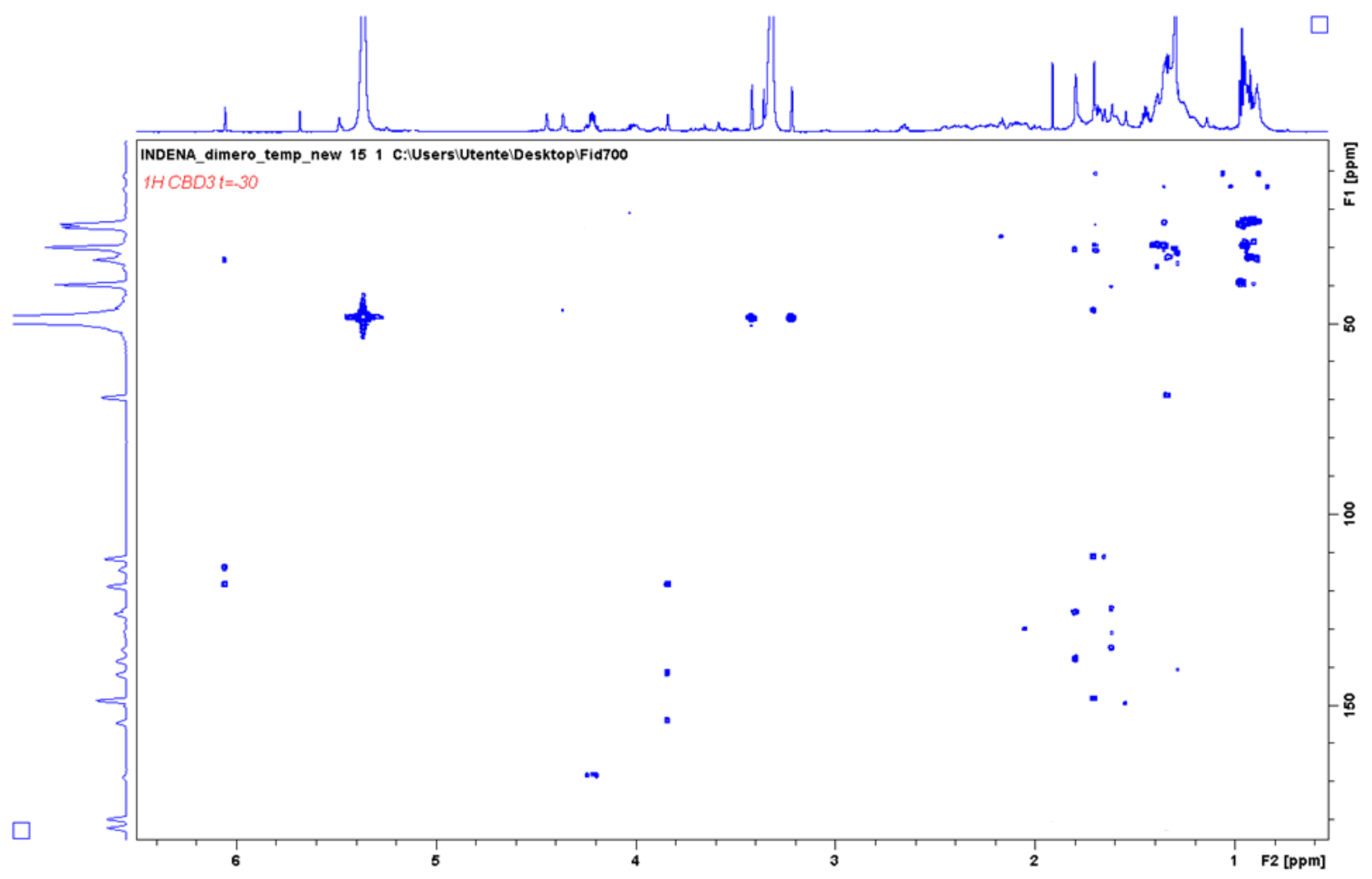

Figure S6. 2D NMR HMBC spectrum of cannabitwinol (3) $(700 \mathrm{MHz})$ in $\mathrm{CD}_{3} \mathrm{OD}$ at $-30^{\circ} \mathrm{C}$

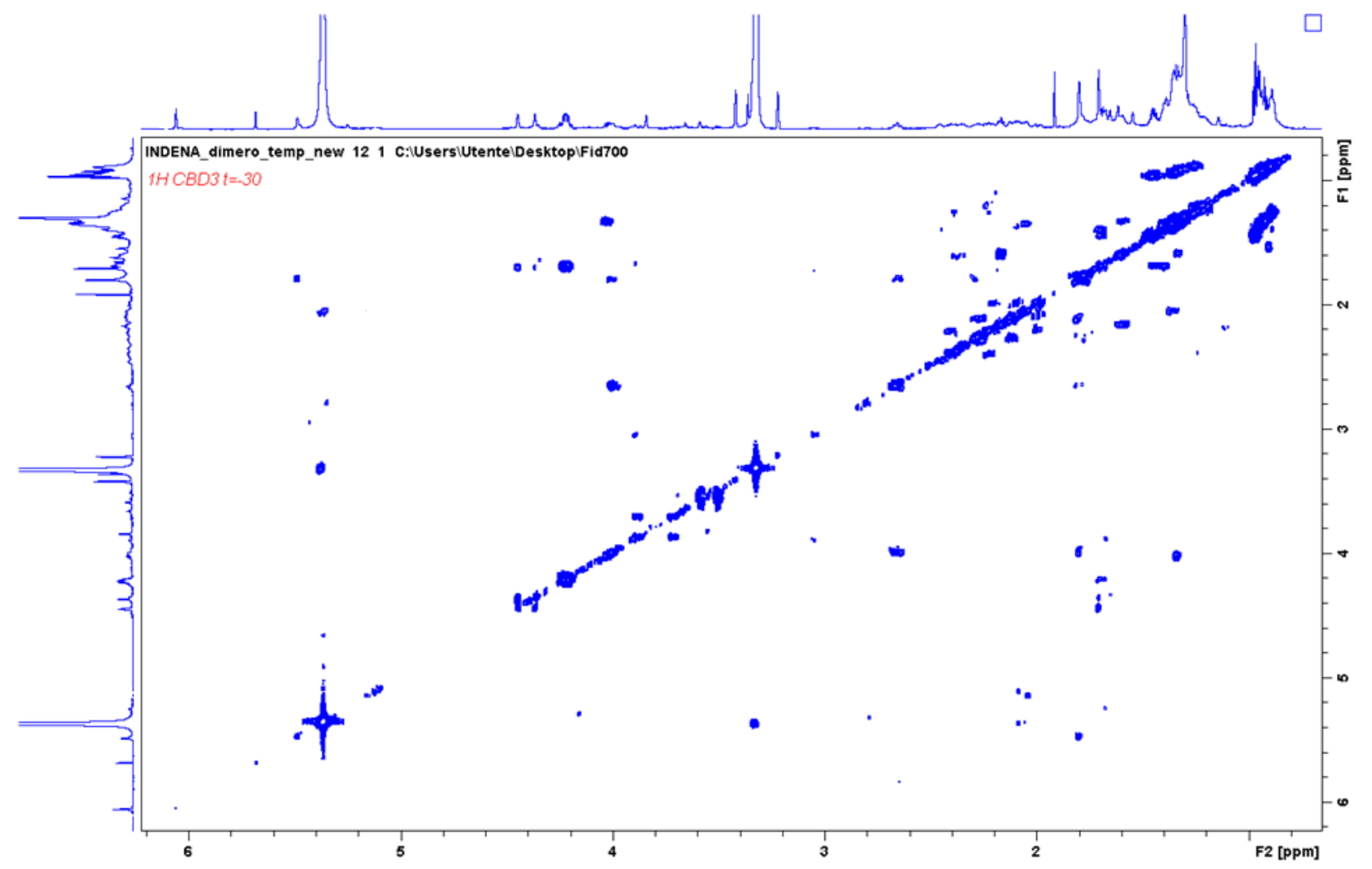

Figure S7. 2D NMR ROESY spectrum of cannabitwinol (3) $(700 \mathrm{MHz})$ in $\mathrm{CD}_{3} \mathrm{OD}$ at $-30{ }^{\circ} \mathrm{C}$ 
SUPPORTING MATERIAL 